syrinx.' Some degree of obstruction usually exists at the foramen magnum, frequently a Chiari-type malformation with prolapse of the cerebellar tonsils. Coughing or straining may then repeatedly cause a transient dissociation of pressures in the cranium and the spine. ${ }^{2}$ Many operations have been devised to decompress this obstruction or to reverse the dynamic forces which distend the syrinx. ${ }^{3-6}$

The dilatation of the spinal cord due to the syrinx may be shown in plain radiographs, which may also show a widened cervical canal and atlantoaxial apposition, or they may otherwise be normal. Myelography using metrizamide and air will confirm the diffuse expansion of the cord, and the air technique may show the collapsing cord sign associated with collapse of a cervical cyst. Computerised tomography may help in showing instances of associated hydrocephalus, in delineating the Chiari malformation, or in indicating basilar invagination.

The results of surgery are not easy to assess ${ }^{6}$ since in untreated patients the condition runs a variable course often with little disability for many years, though in the end they develop severe crippling complications. Long periods of followup have been few in a relatively rare disease, and the substantial operative morbidity and mortality need to be weighed carefully against short-term improvements after the operation. Ventricular shunting will lower the pressure of the cerebrospinal fluid but it carries known hazards and has little logic in the patient whose ventricles are not dilated. In 33 patients followed up for four to 10 years by Love and Olafson ${ }^{7}$ simple incision of the syrinx (syringostomy) produced good (13) or excellent (10) results. Plugging of the communication in the floor of the fourth ventricle by muscle or thread is of uncertain value, especially since the plug may become dislodged.

The most commonly performed operation, recently assessed by Logue and Rice Edwards, ${ }^{6}$ consists of simple decompression at the foramen magnum, combined with syringostomy in certain cases with a deliberate effort to keep the arachnoid intact to avoid blood entering the subarachnoid space. They describe a consecutive series of 75 patients followed up for a mean period of five years. Twenty-one showed neurological improvement in motor function, joint position, and pain and temperature sensations, though no patient returned to normal. In 33 patients the progressive deterioration present before surgery stopped after operation, and their symptoms and signs remained static and stable throughout the follow-up. Patients with pain in the neck or headache after coughing and those with long tract signs in the legs fared best, and in general these were patients in whom a Chiari malformation was the main cause of symptoms. Surgery seemed best avoided in patients with severe disability requiring physical help at the time of assessment. In a comparable appraisal Williams ${ }^{3}$ emphasised the high mortality of operations on the posterior fossa (five out of 41). Morbidity is usually transient and is associated with age and respiratory symptoms, and particularly with pre-existing hydrocephalus, syringobulbia, and arachnoiditis. Unfortunately, the finding of craniospinal pressure dissociation does not give a certain indication of a successful surgical outcome, since the cerebellum may continue to "slump" and become impacted within the bone defect as it previously was in the foramen magnum.

Since no other method is available for altering the clinical course of this disease the modest claims of surgery require serious consideration. Attempts at early surgery to prevent progression are probably not justified in the patient whose symptoms are minimal and whose carefully observed clinical course appears to be stationary with no serious disability. Continued vigilance is, however, necessary in such patients: when signs and incapacity increase investigations should be $\stackrel{\square}{T}$ performed as a prelude to surgery. In a patient whose disability $\frac{3}{\delta}$ is already severe, surgery is unlikely to prove of much benefit but may nevertheless be undertaken as a calculated risk where deterioration is rapid or where headache and pain in the neck are intractable. The hydrodynamic theory of syringomyelia ${ }^{2} 8$ represents a considerable advance, and further investigation of $\mathbb{D}$ surgical methods may yet yield better prospects for the patient.

Consultant Neurologist,

J M S PEARCE

Hull Royal Infirmary

${ }^{1}$ Gardner WJ. The dysraphic states from syringomyelia to anencephaly. Amsterdam: Excerpta Medica, 1973.

2 Williams B. Cerebrospinal fluid pressure changes in response to coughing. Brain 1976;99:331-46.

3 Williams B. A critical appraisal of posterior fossa surgery for communicating syringomyelia. Brain $1978 ; 101: 223-50$.

1 Hankinson J. The surgical treatment of syringomyelia. In: Krayenbuehl $\mathrm{H}$, ed. Advances and technical standards in neurosurgery. Vol 5. Vienna: Springer Verlag, 1978

5 Saez RJ, Onofrio BM, Yanagihara T. Experience with Arnold-Chiari malformation, 1960 to $1970 . \mathcal{F}$ Neurosurg 1976;45:416-22.

${ }^{6}$ Logue V, Edwards MR. Syringomyelia and its surgical treatment-an analysis of 75 patients. F Neurol Neurosurg Psychiatry 1981;44:273-84.

7 Love JG, Olafson RA. Syringomyelia. A look at surgical therapy. $\mathcal{f}$ Neurosurg 1966;24:714-8.

${ }^{8}$ Barnett HJM, Foster JB, Hudgson P, eds. Syringomyelia. London: W B Saunders, 1973.

\section{Adult acute leukaemia: prospects for cure}

The chance that an adult with acute leukaemia-usually acute myeloid leukaemia and less commonly acute lymphoblastic disease-will achieve complete remission after treatment with cytotoxic drugs has increased impressively in recent years. ${ }^{1-3}$ Opinions are divided about the best way to achieve permanent cure. Some believe that further modification of chemotherapy schedules, particularly administration of cytotoxic drugs at relatively high doses immediately after remission (so-called early intensification or consolidation) is most likely to eradicate the disease. Others believe that chemoradiotherapy followed by marrow transplantation, where a suitable marrow donor exists, is the most promising approach. ${ }^{45}$

Though clinical results of these contrasting approaches are now fairly evenly balanced, one or other method is likely to prove clearly superior within a few years. Ideally, a prospective, randomised study comparing the two approaches is necessary and one is now under way at the Sloan-Kettering Institute in New York. ${ }^{6}$ In fact, certain additional criteria are usually required before adults with acute leukaemia in remission are considered for transplantation: they must be relatively young because complications, especially graft-versus-host disease, seem more common and more severe in older patients; they must have an HLA-identical brother or sister as donor; and, perhaps equally important, they must be acquainted with the risks of the procedure and be enthusiastic or at least willing to proceed. The chemotherapy and radiotherapy preceding the marrow transplantation have two functions-to eradicate residual leukaemic cells still present in the marrow (and presumably elsewhere) even in remission and to induce 
sufficient suppression of the patient's immunity to permit the allogeneic marrow to engraft and survive. The precise details of treatment before transplantation vary from centre to centre, but all schedules now include cytotoxic drugs, cyclophosphamide among them, at high dosage followed by whole-body irradiation, also at high dosage. Most patients survive the transplant procedure without major problems. ${ }^{4} 5$ 7 Regrettably, relapse of acute leukaemia still occurs, but the most recent data suggest that $50-60 \%$ of patients with transplants will be long-term survivors and perhaps cured of their leukaemia. ${ }^{8}$

Relapse of acute leukaemia apart, the principal complications of allogeneic marrow transplantation are infection, interstitial pneumonitis of uncertain origin, and graft-versus-host disease. The latter remains the most troublesome and occurs in two somewhat distinct forms, designated "acute" and "chronic." Acute graft-versus-host disease starts soon after transplantation, usually within the first 60 days, and is essentially a three-system disease affecting skin, intestinal tract, and liver; treatment with antilymphocyte globulin is relatively ineffective, ${ }^{10}$ but cyclosporin A can alleviate the cutaneous manifestations, ${ }^{11}$ and high-dose methylprednisolone sometimes produces dramatic responses. ${ }^{12}$ Nevertheless, acute graft-versus-host disease may sometimes prove fatal. Attempts to prevent acute graft-versus-host disease are only moderately effective. The administration of methotrexate in the first 100 days after transplantation may be valuable, and cyclosporin A seems definitely to reduce the severity and perhaps also the frequency of graft-versus-host disease. ${ }^{5}$ Because the reaction may be mediated by immunocompetent cells from the donor, methods are being developed for removing mature $T$ lymphocytes from the donor marrow before infusion to the recipient, either by use of monoclonal or conventional antibodies or by differential centrifugation, ${ }^{1314}$ and early results look encouraging.

Chronic graft-versus-host disease is a protean autoimmunelike disorder, the cause of which, like that of acute graft-versushost disease, is incompletely understood. It starts later, weeks or months after transplantation, and can produce a debilitating skin disease, a generalised sicca syndrome, severe inflammation of the oral and oesophageal mucosa, malabsorption, chronic liver disease, respiratory failure, and increased susceptibility to bacterial infection. ${ }^{15}$ It occurs particularly in patients who have previously had acute graft-versus-host disease and is commoner in older patients; it may be "triggered" by exposure to sunlight or photosensitising drugs. In general, treatment of chronic graft-versus-host disease is unsatisfactory, but the combination of prednisone with azathioprine is helpful in some cases. ${ }^{15}$

If cure of acute leukaemia depends on elimination of the last remaining "clonogenic" leukaemia cell, and if successful transplantation sometimes fails to cure leukaemia, the answer might lie in modification of the chemoradiotherapy used before the operation. The regimen of cytotoxic drugs could in some cases be strengthened, but the dose of radiotherapy is already near the maximum that can be tolerated by certain non-myeloid tissues, especially the lung. Can any other approach be considered ? In 1979 the group in Seattle presented data to suggest that patients given transplants for acute leukaemia (mainly in relapse) who subsequently sustained acute graft-versus-host disease had a lower incidence of recurrent leukaemia than those who had no graft-versus-host disease. ${ }^{16}$ They speculated that differences between donor and recipient at minor histocompatibility loci might be valuable in suppressing or destroying residual leukaemic cells by immunological means. ${ }^{17}$ The incidence of acute graft-versus-host disease following transplantation has probably fallen since 1979, but the Seattle group has more recently reported that the occurrence of chronic graft-versus-host disease also appears to benefit the patient transplanted for leukaemia by reducing the risk of subsequent relapse. ${ }^{18}$ Though there has been some debate about the interpretation of the data, results from other centres support the general conclusion that the graft itself or graftversus-host disease may exert an important antileukaemic effect. A possibility that is now being considered is deliberate induction of chronic graft-versus-host disease, perhaps by infusion of unirradiated donor buffy coat cells in addition to marrow cells. These findings might also mean that transplantation using imperfectly matched donor marrow, such as marrow from HLA-identical unrelated donors or marrow from partially mismatched family members, could have particular antileukaemic activity if the problem of severe graft-versus-host disease can be controlled. A new era for immunotherapy could be dawning.

J M GOLDMAN

Consultant Physician,

MRC Leukaemia Unit,

Royal Postgraduate Medical School,

London W12 OHS

${ }^{1}$ Rees JKH, Sandler RM, Challener J, Hayhoe FGJ. Treatment of acute myeloid leukaemia with a triple cytotoxic regime: DAT. $\mathrm{Br} \mathcal{F}$ Cancer $1977 ; 36: 770-6$

2 Preisler HD, Rustum Y, Henderson ES, et al. Treatment of acute nonlymphocytic leukemia; use of anthracycline-cytosine arabinoside induction therapy and comparison of two maintenance regimens. Blood $1979 ; 53: 455-64$.

${ }^{3}$ Peterson BA, Bloomfield CD. Long-term disease-free survival in acute nonlymphocytic leukemia. Blood 1981;57:1144-7.

4 Thomas ED, Buckner CD, Clift RA, et al. Marrow transplantation for acute nonlymphoblastic leukemia in first remission. $N$ Engl $\mathcal{F}$ Med $1979 ; 301: 597-9$.

5 Powles RL, Morgenstern G, Clink HM, et al. The place of bone-marrow transplantation in acute myelogenous leukaemia. Lancet 1980;i:1047-50.

6 Dinsmore R, Shank B, Kapoor N, et al. A randomised trial of marrow transplantation (BMT) vs chemotherapy (CT) maintenance for acute myelogenous leukemia in first remission: preliminary results. Exp Hematol 1981;9, suppl 9:125.

${ }^{7}$ Mannoni P, Vernant JP, Rodet $\mathrm{M}$, et al. Marrow transplantation for acute nonlymphoblastic leukemia in 1 st remission. Blut $1980 ; 41: 220-4$.

8 Blume KG, Spruce WE, Forman SJ, et al. Bone-marrow transplantation for acute leukemia. $N$ Engl f Med $1981 ; 305: 101-2$

9 Thomas ED. Marrow transplantation for patients with leukemia. Exp Hematol $1981 ; 9$, suppl 9:121.

10 Storb R, Gluckman E, Thomas ED, et al. Treatment of established graft-versus-host disease by antithymocyte globulin. Blood 1974;44: 57-75.

1 Powles RL, Barrett AJ, Clink H, Kay HEM, Sloane J, McElwain TJ. Cyclosporin A for the treatment of graft-versus-host disease in man. Lancet 1978;ii:1327-31.

12 Prentice HG, Bateman SM, Bradstock KF, Hoffbrand AV. High dose methyl prednisolone therapy in established acute graft-versus-host disease. Blut 1980;41:175-6.

${ }^{13}$ Rodt H, Kolb HJ, Netzel B, et al. Effect of anti-T-cell globulin on GVHD in leukemic patients treated with BMT. Transplant Proc $1981 ; 13: 257-61$.

14 Reisner Y, Kapoor N, Kirkpatrick D, et al. Transplantation for acute leukaemia with HLA-A and B nonidentical parental marrow cells fractionated with soybean agglutinin and sheep red blood cells. Lancet $1981 ; \mathrm{ii}: 327-31$

15 Sullivan KM, Shulman HM, Storb R, et al. Chronic graft-versus-host disease in 52 patients: adverse natural course and successful treatment with combination immunosuppression. Blood 1981;57:267.

${ }_{16}$ Weiden PL, Flournoy N, Thomas ED, et al. Antileukemic effect of graft-versus-host disease in human recipients of allogeneic-marrow grafts. $N$ Engl 7 Med 1979;300:1068-73.

1: Weiden PL, Flournoy N, Sanders JE, Sullivan KM, Thomas ED. Antileukemic effect of graft-versus-host disease contributes to improved survival after allogeneic marrow transplantation. Transplant Proc $1981 ; 13: 248-51$.

${ }_{18}$ Weiden PL, Sullivan KM, Flournoy NS, Storb R, Thomas ED. Antileukemic effect of chronic graft-versus-host disease. Contribution to improved survival after allogeneic marrow transplantation. $N$ Englf $M e d$ 1981 ;304:1529-33. 